Research Article

\title{
Simultaneous Determination of Phenolic Acids, Anthraquinones, Flavonoids, and Triterpenes of Cynomorii Herba in Different Harvest Times by LC-MS/MS
}

\author{
Hua Jin, ${ }^{1}$ Ge Tang, ${ }^{2}$ Jin $\mathrm{Li}^{3}{ }^{3}$ Lin $\mathrm{Ma},{ }^{4}$ Yuhong $\mathrm{Li} \mathbb{D},{ }^{3}$ and Yan-xu Chang $\mathbb{D}^{3}$ \\ ${ }^{1}$ College of Traditional Chinese Medicine, Tianjin University of Traditional Chinese Medicine, Tianjin 300193, China \\ ${ }^{2}$ Department of Nephrology, The First Teaching Hospital of Tianjin University of Traditional Chinese Medicine, \\ Tianjin 300193, China \\ ${ }^{3}$ Tianjin State Key Laboratory of Modern Chinese Medicine, Tianjin University of Traditional Chinese Medicine, \\ Tianjin 300193, China \\ ${ }^{4}$ College of Chinese Materia Medica, Tianjin University of Traditional Chinese Medicine, Tianjin 300193, China
}

Correspondence should be addressed to Yuhong Li; liyuhong@tjutcm.edu.cn and Yan-xu Chang; tcmcyx@126.com

Received 3 May 2020; Revised 6 July 2020; Accepted 5 August 2020; Published 26 August 2020

Academic Editor: Antony C. Calokerinos

Copyright $\odot 2020$ Hua Jin et al. This is an open access article distributed under the Creative Commons Attribution License, which permits unrestricted use, distribution, and reproduction in any medium, provided the original work is properly cited.

A sensitive and accurate method was developed for the simultaneous determination of twelve components including phenolic acids (gallic acid, protocatechuic aldehyde, protocatechuic acid, and ferulic acid), flavonoids (catechin, epicatechin, rutin, luteolin, luteolin-7-glucoside, and epicatechin gallate), anthraquinones (emodin), and triterpenes (ursolic acid) in Cynomorii herba in different harvest times by liquid chromatography tandem mass spectrometry (LC-MS/MS). The chromatographic separation was achieved on an Eclipse plus $\mathrm{C}_{18}(3.0 \mathrm{~mm} \times 50 \mathrm{~mm}, 1.8 \mu \mathrm{m})$ column at $40^{\circ} \mathrm{C}$. The mobile phase consisted of acetonitrile and $0.05 \%$ formic acid with a gradient elution at a flow rate of $0.4 \mathrm{~mL} \cdot \mathrm{min}^{-1}$. Under the optimized conditions, there was good linear relation $(r \geq 0.9944)$ and satisfactory precision (RSD values less than 5.65\%). The recoveries of the twelve components were in the range of $93.5-105 \%$. Moreover, the limits of detection (LOD) ranged from 0.003 to $21 \mathrm{ng} \mathrm{mL}^{-1}$ for the twelve analytes. In conclusion, the validated method was successfully applied to analyze the change regularity of the twelve components of Cynomorii herba in different harvest times. It provides a theoretical basis for choosing the suitable harvesting time of Cynomorii herba.

\section{Introduction}

Cynomorii herba (Suoyang in Chinese, $\mathrm{CH}$ ), one kind of traditional Chinese medicines, is the dried succulent stem of Cynomorium songaricum Rupr. It is an edible and medicinal plant that is widely distributed in the northwest desert of China, especially in Inner Mongolia, Ningxia, and Gansu province. It is usually used to make medicated wine and also used as food and fodder in the northwest region of China. $\mathrm{CH}$ has been widely used to improve sexual function, remedy intestinal ailments, postpone senility, nourish kidney, and treat impotence $[1,2]$. Many pharmacological research studies revealed that $\mathrm{CH}$ could improve male fertility by enhancing spermatogenesis and glial-cell-derived neurotrophic factor (GDNF) expression. Moreover, the components of $\mathrm{CH}$ exhibited phytoestrogenic and phytoandrogenic activities, which were benefited for inhibition of oestrogen/androgen-induced BPH development [3-5]. Only one or several components were stipulated as a quality control marker of traditional Chinese medicine in Chinese Pharmacopoeia 2015. However, hundreds of components were existed in TCM, which may possess so many bioactivities. There was no components as a marker for $\mathrm{CH}$ in Chinese Pharmacopoeia 2015 [6]. However, the phytochemical investigation indicated that the main chemistry components of $\mathrm{CH}$ incorporate flavonoids, organic acids, polysaccharides, triterpenes, steroidal compounds, volatile oil, phenolic acids, steroids, alkaloids, and condensed 
tannins [7-9]. These components possessed many bioactivities including antitumor, antioxidant, antiaging, antibacterial activity, and the activities of inhibiting $\mathrm{HCV}$ protease and $\alpha$-glucosidase [10-16]. Thus, it is necessary that multiple components were used for the quality control of $\mathrm{CH}$.

A few analytical methods were established for analyzing chemical constituents of $\mathrm{CH}$, such as thin-layer chromatography, capillary electrophoresis, high-performance liquid chromatography, and ultrahigh-performance liquid chromatography [17-20]. However, these methods suffered from low resolution, low sensitivity, or few analytes (less than five analytes). It was well known that the content of a single or a few compounds might not accurately reflect the quality of the complex herbal products [21]. Therefore, it was necessary to develop a simple and effective method to simultaneously determine multiple components for the quality control of $\mathrm{CH}$.

Moreover, for herbal medicine, the contents of phytochemicals were usually influenced by many factors, such as producing area, harvest time, cultivation techniques, climatic conditions, drying method, and processing method. The constituents and contents of components changed with the harvest time [22, 23]. Therefore, choosing an appropriate harvesting time is the key to ensure the quality and efficiency of medicinal materials. In addition, the major source of $\mathrm{CH}$ is wild in traditional Chinese medicine. Due to the excessive collection and nonstandard collection methods, the wild resources of $\mathrm{CH}$ have decreased sharply in recent years. The artificial cultivation helped protecting the ecological environment and resource of $\mathrm{CH}$. Thus, comparing the difference of components contents in wild and cultivated $\mathrm{CH}$ is necessary for ensuring the quality of medicinal materials.

The aim of this study was to establish a rapid and sensitive LC-MS/MS method for simultaneous determination of phenolic acids (gallic acid, protocatechuic aldehyde, protocatechuic acid, and ferulic acid), flavonoids (catechin, epicatechin, rutin, luteolin, luteolin-7-glucoside, and epicatechin gallate), anthraquinones (emodin), and triterpenes (ursolic acid) in wild and cultivated $\mathrm{CH}$ samples in different harvesting seasons (Figure 1). A validated method can be used as a valid analytical method for intrinsic quality control of $\mathrm{CH}$. Moreover, the quantitative analysis results can be helpful for choosing the best harvesting season of $\mathrm{CH}$.

\section{Materials and Methods}

2.1. Materials and Reagents. Reference standards of gallic acid, caffeic acid (IS1), protocatechuic aldehyde, protocatechuic acid, ferulic acid, luteolin, luteolin-7-glucoside, catechin, epicatechin, emodin, and ursolic acid were purchased from the Chinese National Institute of Control of Pharmaceutical and Biological Products (Beijing, China). Epicatechin gallate, astragalin (IS2), and rutin were obtained from Chengdu Must Bio-Technology Co., Ltd. (Chengdu, China). The purity of all references is over $98.0 \%$. Acetonitrile and formic acid of HPLC grade were achieved from Merck (Germany). The water with ultrapure grade was obtained from Milli-Q Water System (Millipore, USA). Other reagents were of analytical grade.

2.2. Herbal Plant. The Cynomorii herba, both wild and cultivated, were collected from Inner Mongolia province in China in different harvest times. The Cynomorii herba were identified by Professor Yan-xu Chang (Tianjin University of Traditional Chinese Medicine), and the voucher specimens were deposited at the Tianjin University of Traditional Chinese Medicine. First, the fresh samples were dried natural. Then, they were dried in oven at $105^{\circ} \mathrm{C}$ until constant weight was obtained. Finally, these samples were smashed into powder using a pulverizer and passed through a 60mesh sieve, which were prepared for the following experiment.

\subsection{Chromatographic and Mass Spectrometric Conditions.} The Agilent series 1200 HPLC system, which equipped with Agilent 6430 triple quadrupole mass spectrometer, was used for chromatographic analysis. All separations were carried out on an Agilent Eclipse plus $\mathrm{C}_{18}(3.0 \mathrm{~mm} \times 50 \mathrm{~mm}$ i.d., $1.8 \mu \mathrm{m})$ column. The mobile phases consisted of $(A)$ aqueous formic acid $(0.05 \%, v / v)$ and $(B)$ acetonitrile. The gradient elution was as follows: $0-7 \mathrm{~min}, 10-25 \% \mathrm{~B} ; 7-10 \mathrm{~min}, 25-90 \% \mathrm{~B}$; and $10-15 \mathrm{~min}, 90-90 \% \mathrm{~B}$ at a flow rate of $0.4 \mathrm{~mL} \cdot \mathrm{min}^{-1}$. The aliquot of $4 \mu \mathrm{L}$ was injected. In addition, the pressure of MS nebulizer was $35 \mathrm{psi}$. The flow rate and temperature of dried gas were $10 \mathrm{~L} \mathrm{~min}^{-1}$ and $325^{\circ} \mathrm{C}$, respectively. The mass spectrometric parameters of all analytes were listed in Table 1.

\subsection{Preparation of Internal Standard and Quality Control} (QC) Samples. Caffeic acid and astragalin were dissolved with methanol to make a mixed internal standard (IS) solution at a concentration of $100 \mathrm{ng} \mathrm{mL}^{-1}$. Each standard $(10 \mathrm{mg})$ was dissolved by $10 \mathrm{~mL}$ methanol for preparing the twelve stock solutions. Quality control (QC) samples of the twelve components were prepared at medium concentration level by dissolving appropriate mixed standard solution in methanol, respectively. Then, a series of working standard solutions was achieved by mixing the twelve stock solution and diluted with methanol before use, including gallic acid, protocatechuic acid, catechin, protocatechuic aldehyde, epicatechin, ferulic acid, rutin, epicatechin gallate, luteolin-7-glucoside, luteolin, emodin, and ursolic acid in the range of 101-5050, 20.2-5050, 204-10200, 44.8-1120, 21.6-1080, 8.16-1020, 20.8-1040, 20.2-5050, 20.2-1010, 20.2-1010, 0.4-20, and 7.92-198 ng mL -1 , respectively. All solutions were stored at $4^{\circ} \mathrm{C}$.

2.5. Sample Solution Preparation. The samples were powdered and passed through a 60-mesh sieve. The accurately weighed sample powder $(0.100 \mathrm{~g})$ was ultrasonic extracted with $10 \mathrm{~mL}$ of $70 \%(\mathrm{v} / \mathrm{v})$ methanol for $20 \mathrm{~min}$, cooled at room temperature, and subsequently centrifuged for $10 \mathrm{~min}$ at $14000 \mathrm{rpm}$. Then, IS $(10 \mu \mathrm{L})$ was added to the supernatant $(990 \mu \mathrm{L})$. The final solutions were vortexed for 30 seconds and centrifuged for $10 \mathrm{~min} .4 \mu \mathrm{L}$ of the supernatant was injected into the HPLC. 
<smiles>O=C(O)c1cc(O)c(O)c(O)c1</smiles>

Gallic acid (1)

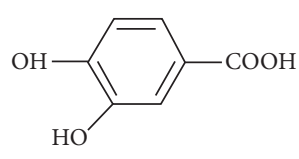

Protocatechuic acid (2)<smiles>Oc1cc(O)c2c(c1)O[C@H](c1ccc(O)c(O)c1)[C@H](O)C2</smiles><smiles>CC[C@H]1O[C@@H](Oc2c(-c3ccc(O)c(O)c3)oc3cc(O)cc(O)c3c2=O)[C@H](O)[C@@H](O)[C@@H]1O</smiles><smiles>C[C@@H]1OC(=O)[C@H](O)[C@@H](O)[C@@H]1O</smiles><smiles>O=Cc1ccc(O)c(O)c1</smiles>

Protocatechuic aldehyde (4)<smiles>O=C(O[C@@H]1Cc2c(O)cc(O)cc2O[C@H]1c1ccc(O)c(O)c1)c1cc(O)c(O)c(O)c1</smiles>

Epicatechin (5)<smiles>COc1cc(/C=C/C(=O)O)ccc1O</smiles><smiles>O=c1cc(-c2ccc(O)c(O)c2)oc2cc(O)cc(O)c12</smiles>

$\mathrm{OH}$<smiles>O=c1cc(-c2ccc(O)c(O)c2)oc2cc(OC3OC(CO)C(O)C(O)C3O)cc(O)c12</smiles>

Luteolin-7-glucoside (9)<smiles>Cc1cc(O)c2c(c1)C(=O)c1cc(O)cc(O)c1C2=O</smiles>

Emodin (11)

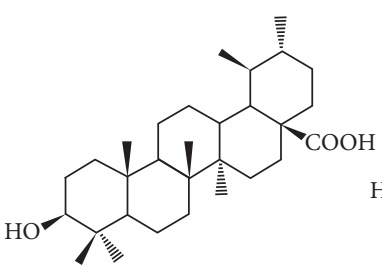

Ursolic acid (12)<smiles>O=C(O)/C=C/c1ccc(O)c(O)c1</smiles>

Caffeic acid (IS1)<smiles>O=c1c(O[C@@H]2O[C@H](CO)[C@@H](O)[C@H](O)[C@H]2O)c(-c2ccc(O)cc2)oc2cc(O)cc(O)c12</smiles>

Figure 1: Chemical structures of twelve components and IS.

TABLE 1: Mass spectrometric parameters for all analytes.

\begin{tabular}{lcccc}
\hline Compounds & $\begin{array}{c}\text { Precursor } \\
\text { ion }\end{array}$ & $\begin{array}{c}\text { Product } \\
\text { ion }\end{array}$ & Fragmentor & CE \\
\hline Gallic acid & 169.0 & 125.0 & 90 & 8 \\
Protocatechuic acid & 153.0 & 108.8 & 75 & 9 \\
Catechin & 288.9 & 245.0 & 140 & 10 \\
Protocatechuic & 136.9 & 107.5 & 100 & 19 \\
aldehyde & 289.0 & 245.0 & 145 & 10 \\
Epicatechin & 193.1 & 133.8 & 75 & 10 \\
Ferulic acid & 609.0 & 300.0 & 235 & 39 \\
Rutin & 441.0 & 288.9 & 150 & 10 \\
Epicatechin gallate & 447.0 & 284.9 & 210 & 25 \\
Luteolin-7-glucoside & 285.0 & 133.0 & 160 & 33 \\
Luteolin & 269.0 & 225.0 & 140 & 21 \\
Emodin & 455.2 & 455.2 & 115 & 0 \\
Ursolic acid & 179.0 & 135.0 & 90 & 10 \\
Caffeic acid (IS1) & 447.0 & 283.9 & 180 & 25 \\
Astragalin (IS2) & & & &
\end{tabular}

2.6. Method Validation. These analytes of standard stock solutions were diluted to a series of appropriate concentrations for plotting the calibration curves. Then, the curves were constructed by plotting the peak areas versus the concentration of each analyte.
The QC samples at three levels of different concentration were applied to evaluate the accuracy and precision in same day (intraday) and between three different days (interday). The assessed index was RSD and the percent ratios of the calculated concentration to nominal concentration. The range of accuracy should be 95.0 to $105 \%$.

Stability study was performed with sample solution in $24 \mathrm{~h}$ (the time-point is $0,2,4,6,8,12$, and $24 \mathrm{~h}$, respectively) at the condition of temperature. The repeatability was investigated by using the developed method parallelly six times.

The recovery was tested by adding mixed reference standard solution to the untreated sample to yield final concentration. The sample was processed by the sample preparation procedure $(n=6)$.

\section{Results}

3.1. Internal Standard (IS) Selection. In the study, the four kinds of compounds were simultaneously determined. Caffeic acid and astragalin were chosen as internal standard for phenolic acid, flavonoid, anthraquinone, and triterpene and no interference from endogenous substances. 


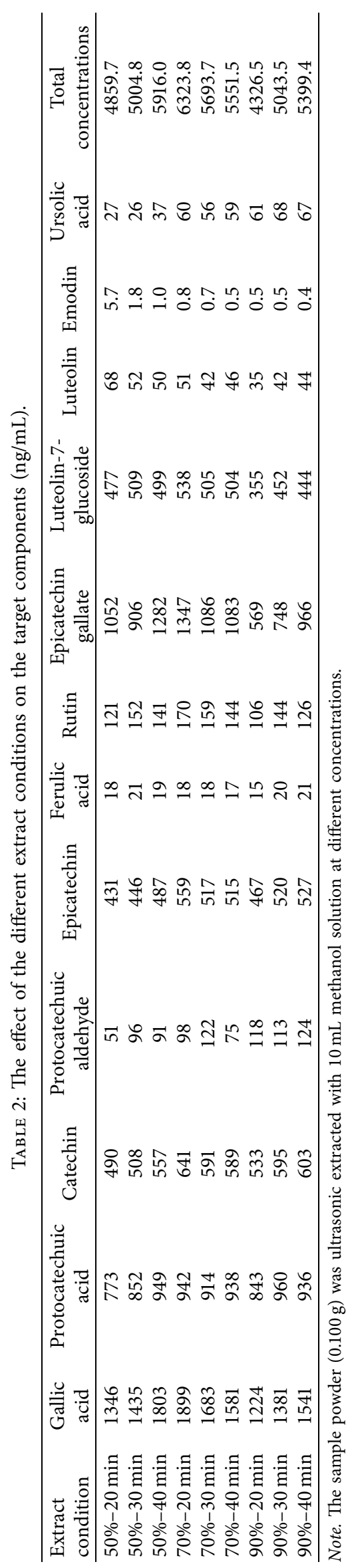




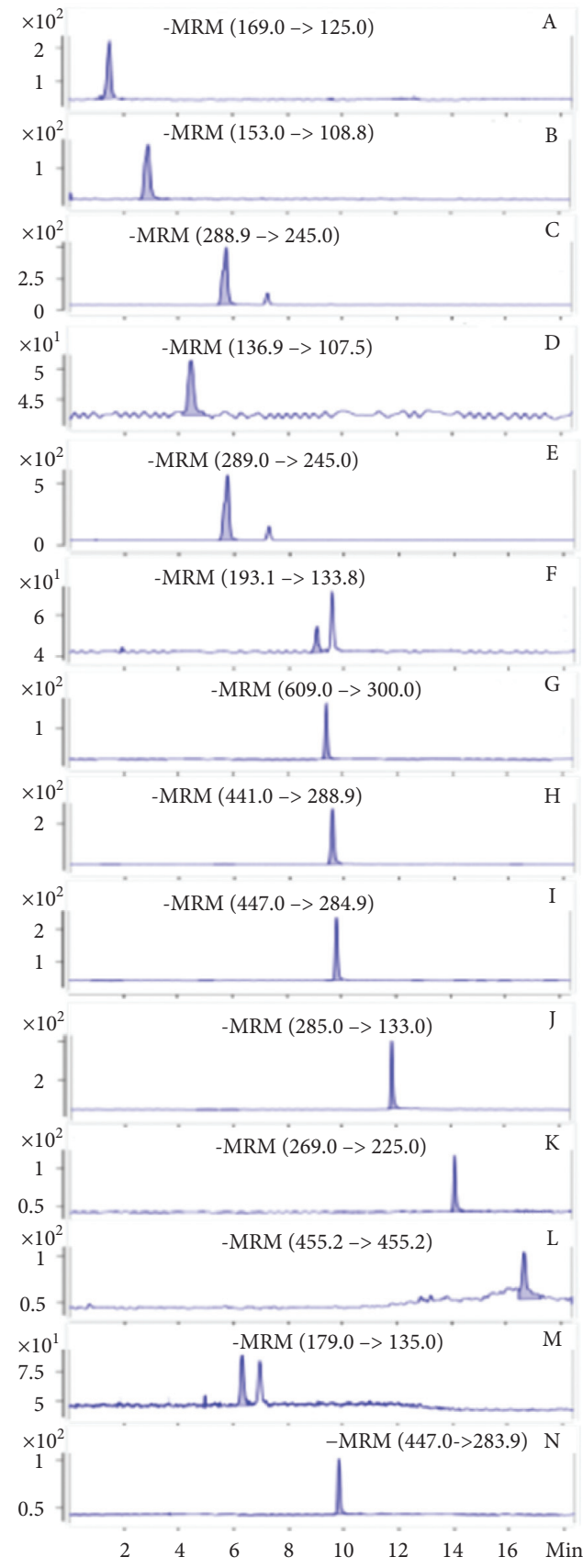

(a)

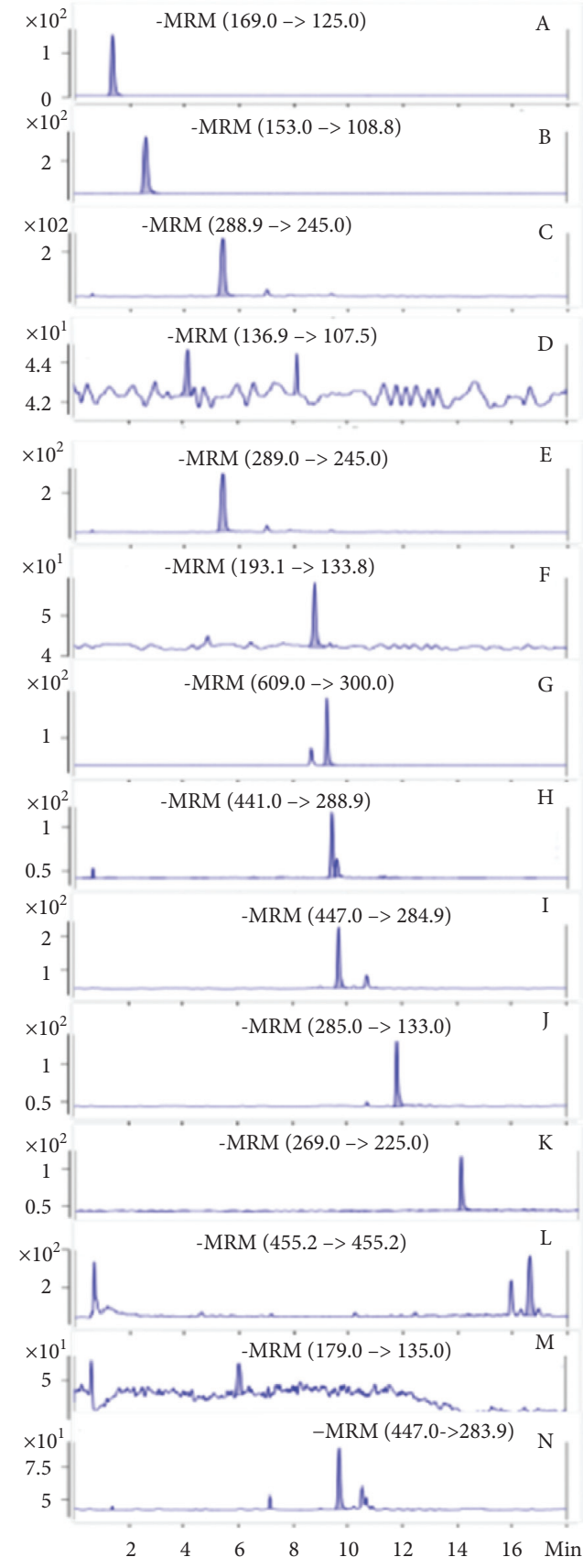

(b)

Figure 2: Representative chromatograms of (a) mixed standard solution and (b) the real sample solution of gallic acid (A), protocatechuic acid (B), catechin (C), protocatechuic aldehyde (D), epicatechin (E), ferulic acid (F), rutin (G), epicatechin gallate (H), luteolin-7-glucoside (I), luteolin (J), emodin (K), ursolic acid (L), caffeic acid $(\mathrm{M})$, and astragalin $(\mathrm{N})$.

3.2. Optimization of Extraction Conditions. In order to achieve an optimum extraction of target components in $\mathrm{CH}$, the key factors such as methanol concentration (50, 70 and $90 \%, \mathrm{v} / \mathrm{v})$ and ultrasonic time (20, 30 and $40 \mathrm{~min})$ were investigated by using combination experiment, while sample-solvent ratio $(1: 100, \mathrm{w} / \mathrm{v})$ was kept constant. Total concentration of the twelve target components in the extract solution was selected as the evaluating indicator (Table 2). It was found that total concentration of the twelve target components in the extract solution was $6323.8 \mathrm{ng} / \mathrm{mL}$ when $70 \%(\mathrm{v} / \mathrm{v})$ methanol was selected to extract the target components for $20 \mathrm{~min}$ in ultrasonic extraction process. Finally, the optimum condition was obtained when the sample was extracted by $70 \%(\mathrm{v} / \mathrm{v})$ methanol for $20 \mathrm{~min}$.

3.3. Optimization of HPLC-MS/MS Conditions. To obtain good chromatographic separation, various HPLC 
TABLE 3: Precision and stability of twelve components $(n=6)$.

\begin{tabular}{|c|c|c|c|c|c|c|c|}
\hline \multirow{2}{*}{ Components } & \multirow{2}{*}{ Concentration $\left(\mathrm{ng} \cdot \mathrm{mL}^{-1}\right)$} & \multicolumn{2}{|c|}{ Intraday } & \multicolumn{2}{|c|}{ Interday } & \multicolumn{2}{|c|}{ Stability $(n=6)$} \\
\hline & & RSD (\%) & Accuracy (\%) & RSD (\%) & Accuracy (\%) & RSD (\%) & Accuracy (\%) \\
\hline Gallic acid & 505 & 3.1 & 103.7 & 0.1 & 103.7 & 3.08 & 96.6 \\
\hline Protocatechuic acid & 505 & 3.5 & 103.9 & 0.6 & 104 & 2.38 & 101.5 \\
\hline Catechin & 5100 & 3.1 & 103.2 & 1.8 & 101.1 & 3.70 & 94.6 \\
\hline Protocatechuic aldehyde & 560 & 2.4 & 103.3 & 1.7 & 104.2 & 5.34 & 102.8 \\
\hline Epicatechin & 540 & 2.4 & 104.8 & 1.6 & 104.2 & 3.54 & 95.3 \\
\hline Ferulic acid & 102 & 2.6 & 100.5 & 3.2 & 98.7 & 3.43 & 103.0 \\
\hline Rutin & 104 & 4.2 & 103.4 & 2.2 & 102.6 & 5.83 & 96.1 \\
\hline Epicatechin gallate & 505 & 2.6 & 104.5 & 2.0 & 102.9 & 8.32 & 82.6 \\
\hline Luteolin-7-glucoside & 101 & 3.2 & 103.7 & 1.2 & 102.9 & 4.70 & 104.9 \\
\hline Luteolin & 100 & 3.0 & 102.7 & 2.9 & 101.3 & 8.98 & 93.6 \\
\hline Emodin & 2 & 4.4 & 101.1 & 1.2 & 102.0 & 4.53 & 110.8 \\
\hline Ursolic acid & 99 & 3.1 & 103.3 & 0.5 & 103.3 & 5.58 & 105.9 \\
\hline
\end{tabular}

TABLe 4: Calibration curves, LOD, LOQ, Repeatability, and Recovery of all analytes $(n=6)$.

\begin{tabular}{|c|c|c|c|c|c|c|c|c|}
\hline \multirow[b]{2}{*}{ Components } & \multirow[b]{2}{*}{ Linear regression } & \multirow[b]{2}{*}{$\begin{array}{l}\text { Linear range } \\
\left(\text { ng } \cdot \mathrm{mL}^{-1}\right)\end{array}$} & \multirow[b]{2}{*}{$r^{2}$} & \multirow[b]{2}{*}{$\begin{array}{c}\mathrm{LOD} \\
\left(\mathrm{ng} \cdot \mathrm{mL}^{-1}\right)\end{array}$} & \multirow[b]{2}{*}{$\begin{array}{c}\text { LOQ } \\
\left(\text { ng } \cdot \mathrm{mL}^{-1}\right)\end{array}$} & \multirow[b]{2}{*}{$\begin{array}{l}\text { Repeatability } \\
\text { RSD (\%) }\end{array}$} & \multicolumn{2}{|c|}{ Recovery } \\
\hline & & & & & & & $\begin{array}{c}\text { Mean } \\
(\%)\end{array}$ & $\begin{array}{l}\text { RSD } \\
(\%)\end{array}$ \\
\hline Gallic acid & $Y=0.2895 X+0.0354$ & $101-5050$ & 0.9994 & 5 & 15 & 5.75 & 94.0 & 3.08 \\
\hline $\begin{array}{l}\text { Protocatechuic } \\
\text { acid }\end{array}$ & $Y=0.1929 \mathrm{X}-0.0040$ & $20.2-5050$ & 0.9994 & 6 & 18 & 4.32 & 95.5 & 4.00 \\
\hline Catechin & $Y=0.1018 X+0.0280$ & $204-10200$ & 0.9998 & 6 & 18 & 5.48 & 101.6 & 6.43 \\
\hline $\begin{array}{l}\text { Protocatechuic } \\
\text { aldehyde }\end{array}$ & $Y=0.0122 X+0.0034$ & $44.8-1120$ & 0.9998 & 1.5 & 4 & 3.71 & 100.5 & 5.04 \\
\hline Epicatechin & $Y=0.9618 X+0.0280$ & $21.6-1080$ & 0.9998 & 7 & 21 & 3.11 & 97.7 & 5.12 \\
\hline Ferulic acid & $\begin{array}{c}Y=0.1414 X-2.2003 e- \\
004\end{array}$ & $20.2-1020$ & 0.9995 & 3 & 10 & 7.36 & 99.3 & 5.53 \\
\hline Rutin & $Y=0.9379 \mathrm{X}-0.0038$ & $20.8-1040$ & 0.9996 & 0.5 & 1.5 & 7.86 & 98.1 & 5.83 \\
\hline Epicatechin gallate & $Y=0.3410 \mathrm{X}-0.0124$ & $20.2-5050$ & 0.9994 & 1 & 3 & 6.93 & 97.7 & 6.63 \\
\hline $\begin{array}{l}\text { Luteolin-7- } \\
\text { glucoside }\end{array}$ & $Y=1.6412 X+0.0779$ & $20.2-1010$ & 0.9998 & 0.1 & 0.3 & 2.64 & 105.0 & 4.28 \\
\hline Luteolin & $Y=21.2695 X+17.0019$ & $20.2-1010$ & 0.9990 & 0.1 & 0.3 & 2.35 & 102.5 & 3.71 \\
\hline Emodin & $Y=5.3529 X+0.0097$ & $0.4-20$ & 0.9997 & 0.003 & 0.01 & 0.00 & 104.3 & 2.24 \\
\hline Ursolic acid & $Y=0.1071 X+1.1690$ & $7.92-198$ & 0.9944 & 0.3 & 1.0 & 9.10 & 93.5 & 1.43 \\
\hline
\end{tabular}

parameters including mobile phase modifier $(0,0.05,0.1$, and $0.2 \%$ formic acid), column temperature $(35,40$, and $\left.45^{\circ} \mathrm{C}\right)$, and flow rate $\left(0.3,0.4\right.$ and $\left.0.5 \mathrm{~mL} \cdot \mathrm{min}^{-1}\right)$ were also investigated in detail for analyzing the target compounds. Take into consideration the peak response and separation, the optimum HPLC conditions were obtained when mobile phase modifier was $0.05 \%$ formic acid, column temperature was $40{ }^{\circ} \mathrm{C}$, and flow rate was $0.4 \mathrm{~mL} \cdot \mathrm{min}^{-1}$.

Twelve components were identified by comparing their retention time and the MS information with those of reference standards, respectively. The results showed that the highest sensitivity was obtained at a certain value of collision energy (CE).

\subsection{Method Validation}

3.4.1. Specificity. Figure 2 showed the chromatograms of twelve compounds of $\mathrm{CH}$ in the MRM mode. The results demonstrated that there was good separation and no interference from endogenous components for all analytes.
3.4.2. Precision and Stability. The accuracy was achieved by evaluating QC samples of twelve components in one day $(n=6)$. The accuracies of twelve components for intraday and interday within range of $87.2-107.3 \%$. The RSD value was below $5.65 \%$ (Table 3 ). These results demonstrated that the developed method was accurate and reproducible.

The stabilities of the twelve components were determined at $0 \mathrm{~h}, 2 \mathrm{~h}, 4 \mathrm{~h}, 6 \mathrm{~h}, 8 \mathrm{~h}, 12 \mathrm{~h}$, and $24 \mathrm{~h}$, respectively. As present in Table 3, the RSD values were below $8.98 \%$. The results indicated that there was good stability within $24 \mathrm{~h}$ for all analytes.

3.4.3. Calibration Curves, Limit of Detection (LOD), Limit of Quantification (LOQ), Repeatability, and Recovery. Under the optimum chromatographic conditions, all calibration curves of the twelve components were achieved with wide concentration ranges and the correlation coefficients of them were greater than 0.9944 . For the twelve components, the LOD ranged from 0.003 to $21 \mathrm{ng} \mathrm{mL}^{-1}$, and the limit of LOQ ranged from 0.01 to $18 \mathrm{ng} \mathrm{mL}^{-1}$. RSD values of the 


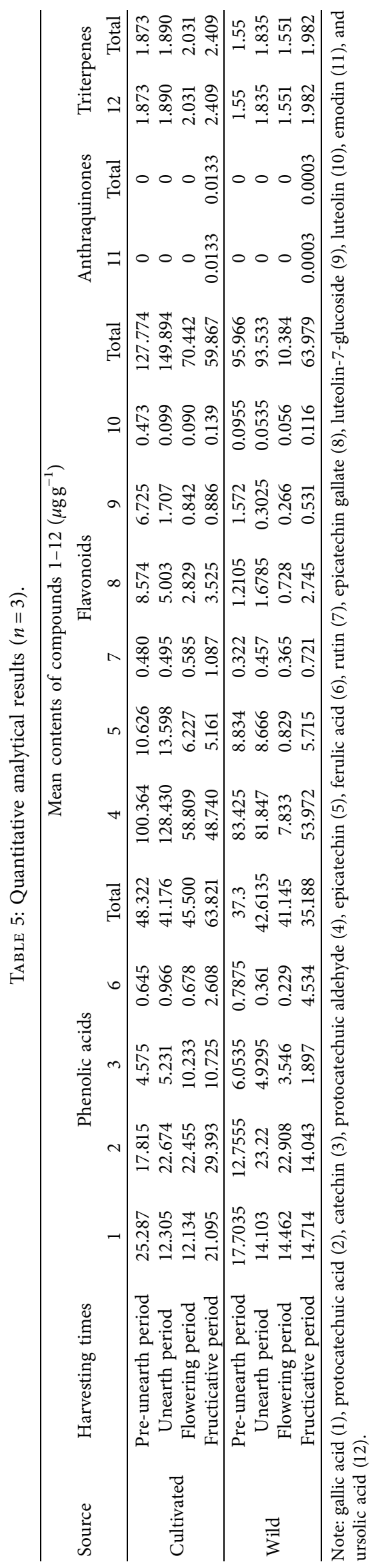


repeatability were less than $9.10 \%$. These results were shown in Table 4.

The recovery was performed for evaluating the precision and accuracy of the established method. The recoveries of twelve compounds were in range of 93.5-105.0\%, and their RSD values were less than $6.63 \%$ (Table 4 ). The above results indicated that the developed method possessed good accuracy and precision.

3.5. Analysis of Four Kinds of Components (Phenolic Acid, Flavonoid, Anthraquinone, and Triterpene) at Different Harvest Times and from Different Sources. The established method was applied to simultaneously determine the twelve components of $\mathrm{CH}$ at four different harvesting times and from two different sources (wild and cultivated). The variation of contents of twelve components in different harvest times and sources were shown in Table 5.

For different sources, the results revealed that the total contents of the four kinds of components including phenolic acids, flavonoids, anthraquinones, and triterpenes in the cultivated sample were higher than those of the four kinds of components in the wild sample in four harvesting times. Therefore, cultivated $\mathrm{CH}$ can be used instead of wild $\mathrm{CH}$. Artificial cultivation has solved the problems such as resource scarcity and destruction of ecological environment for $\mathrm{CH}$.

For different harvest times, the contents of phenolic acids (protocatechuic acid, catechin, and ferulic acid) and the total phenolic acid were the highest in fructicative period. Compared with the other periods, the content of gallic acid was higher in pre-unearth period. Emodin (anthraquinones) was detected only in the sample at fructicative period. Moreover, the content of ursolic acid (triterpenes) was highest during fructicative period. These results indicated that the fructicative period could be the optimum harvest time for anthraquinones and triterpenes. In addition, the contents of flavonoids (epicatechin gallate, luteolin7-glucoside, luteolin) were highest in pre-unearth period. The contents of protocatechuic aldehyde, epicatechin, and total flavonoids were higher in unearth period.

To sum up, for the three kinds of components (phenolic acid, anthraquinones, and triterpenes), the productive period was the optimum harvest time. However, the unearth period was the appropriate harvest time for flavonoids. Because Cynomorium songaricum is a parasitic plant, its standardized cultivation is difficult. At present, Cynomorium songaricum was only cultivated in one area in Inner Mongolia of China. In the future, more cultivated and wild samples with different harvesting times should be analyzed to support the results and conclusion by the established LCMS/MS method.

\section{Conclusions}

A simple and effective method was developed for the simultaneous determination of the twelve components in wild and cultivated Cynomorii herba in different harvest times. The results indicated that the established method possessed excellent sensitivity and selectivity. Moreover, the application of this method could successfully evaluate the quality of wild and cultivated $\mathrm{CH}$. It is crucial for solving the problem of resource scarcity.

In addition, the contents of the four kinds of components varied with the different harvest period. We can choose the optimum harvest time according to the requirements of different types of chemical ingredients. Consequently, the developed HPLC-MS/MS method provided the theoretic basis for quality control and resource protection of $\mathrm{CH}$.

\section{Data Availability}

The data used to support the findings of this study are available from the corresponding author upon request.

\section{Conflicts of Interest}

The authors declare no conflicts of interest.

\section{Authors' Contributions}

Conceptualization of the study was done byYuhong Li and Yan-xu Chang. Data curation was by Hua Jin, Ge Tang, Jin Li and Yuhong Li. Formal analysis was performed by Hua Jin, Ge Tang, Jin Li and Yuhong Li. Funding acquisition was carried out by Yan-xu Chang. Investigation and original draft preparation was carried out by Hua Jin, Ge Tang, Lin Ma, Yuhong Li, Jin Li, and Yan-xu Chang. Lin Ma and Yanxu Chang reviewed and edited the draft. Hua Jin and Ge Tang have contributed equally to this work.

\section{Acknowledgments}

This research was supported by the Tianjin Research Program of Application Foundation and Advanced Technology (18JCYBJC95000) and Special Program of Talents Development for Excellent Youth Scholars in Tianjin.

\section{References}

[1] H. P. Liu, R. F. Chang, Y. S. Wu, W. Y. Lin, and F. J. Tsai, "The yang-tonifying herbal medicine Cynomorium songaricum extends lifespan and delays aging in Drosophila," EvidenceBased Complementary and Alternative Medicine, vol. 2012, Article ID 735481, 11 pages, 2012.

[2] C. Z. Zhang, S. X. Wang, Y. Zhang, J. P. Chen, and $X$. M. Liang, "In vitro estrogenic activities of Chinese medicinal plants traditionally used for the management of menopausal symptoms," Journal of Ethnopharmacology, vol. 98, pp. 295-300, 2005.

[3] J. S. Lee, H. A. Oh, J. Y. Kwon et al., "The effects of Cynomorium songaricum on the reproductive activity in male golden hamsters," Development and Reproduction, vol. 17, pp. 37-43, 2013.

[4] W. M. Yang, H. Y. Kim, S. Y. Park, H. M. Kim, M. S. Chang, and S. K. Park, "Cynomorium songaricum induces spermatogenesis with glial cell-derived neurotrophic factor (GDNF) enhancement in rat tests," Journal of Ethnopharmacology, vol. 128, pp. 693-696, 2010. 
[5] X. N. Wang, R. Tao, J. Yang et al., "Compounds from Cynomorium songaricum with estrogenic and androgenic activities suppress the oestrogen/androgen-induced BPH process," Evidence-Based Complementary and Alternative Medicine, vol. 5, 2017.

[6] The State of Commission Chinese Pharmacopoeia, Pharmacopoeia of the People's Republic of China, China Medical Science and Technology Press, Beijing, China, 2015.

[7] S. Tuvaanjav, H. Shuqin, M. Komata et al., "Isolation and antiviral activity of water soluble Cynomorium songaricum Rupr. polysaccharides," J Journal of Asian Natural Products Research, vol. 18, pp. 159-171, 2016.

[8] G. E. Su and Y. X. Chang, "Research status of the chemical constituents and pharmacological effects of Cynomorium songaricum Rupr," Chinese Journal of Natural Medicines, vol. 6, pp. 46-49, 2005.

[9] H. C. Meng, S. Wang, Y. Li, Y. Y. Kuang, and C. M. Ma, "Chemical constituents and pharmacological actions of Cynomorium plants," Chinese Journal of Natural Medicines, vol. 11, pp. 321-329, 2013.

[10] P. Y. Maximov, T. M. Lee, and V. Craig Jordan, “The discovery and development of selective estrogen receptor modulators (SERMs) for clinical practice," Current Clinical Pharmacology, vol. 8, pp. 126-131, 2013.

[11] H. C. Meng and C. M. Ma, "Flavan-3-ol-cysteine and acetylcysteine conjugates from edible reagents and the stem of Cynomorium songaricum as potent antioxidants," Food Chemistry, vol. 141, pp. 2691-2696, 2013.

[12] Y. Liu, H. Li, X. Wang, G. Zhang, Y. Wang, and D. Di, "Evaluation of the free radical scavenging activity of Cynomorium songaricum Rupr by a novel DPPH-HPLC method," Journal of Food Science, vol. 76, pp. 1245-1249, 2011.

[13] H. P. Liu, R. F. Chang, Y. S. Wu, W. Y. Lin, and F. J. Tsai, "The Yang-Tonifying herbal medicine Cynomorium songaricum extends lifespan and delays aging in Drosophila," EvidenceBased Complementary and Alternative Medicine, vol. 15, 2012.

[14] S. W. Jin, Eerdunbayaer, A. Doi, T. Kuroda, G. X. Zhang, and G. L. Chen, "Polyphenolic constituents of Cynomorium songaricum Rupr and antibacterial effect of polymeric proanthocyanidin on methicillin-resistant staphylococcus aureus," Journal of Agricultural and Food Chemistry, vol. 60, pp. 7297-7305, 2012.

[15] C. M. Ma, X. Y. Li, N. Nakamura, and M. Hattori, "Flavan-3ol contents, antioxidative and $\alpha$-glucosidase inhibitory activities of Cynomorium songaricum," Food Chemistry, vol. 118, pp. 116-119, 2010.

[16] C. M. Ma, Y. Wei, Z. G. Wang, and M. Hattori, “Triterpenes from Cynomorium songaricum analysis of $\mathrm{HCV}$ protease inhibitory activity, quantification, and content change under the influence of heating," Journal of Natural Medicines, vol. 63, pp. 9-14, 2009.

[17] S. C. Yang, R. F. Ou, and K. P. Lai, "The determination of emodin, physcion and Chrysophanol in Polygonum multiflorum Thunb by TLC, Chin," Journal of Clinicl. Rational Drug Use.vol. 3, pp. 73-74, 2010.

[18] J. Koyama, I. Morita, K. Kawanishi, K. Tagahara, and N. Kobayashi, "Capillary electrophoresis for simultaneous determination of emodin, chrysophanol, and their 8-beta-Dglucosides," Chemical and Pharmaceutical Bulletin, vol. 51, pp. 418-420, 2003.

[19] L. X. Yan, D. Qi, and Z. H. Feng, "Simultaneous quantitative determination of eight components in Polygonum multiflorum Thunb by RP-HPLC," Journal of Chinese Pharmaceutical Sciences, vol. 18, pp. 358-361, 2009.
[20] L. F. Han, B. Wu, G. X. Pan, Y. F. Wang, X. B. Song, and X. M. Gao, "UPLC-PDA analysis for simultaneous quantification of four active compounds in crude and processed rhizome of polygonum multiflorum thumb," Journal of Chromatography A, vol. 70, pp. 657-659, 2009.

[21] T. Xue and R. Roy, "Studying traditional Chinese medicine," Science, vol. 300, pp. 740-741, 2003.

[22] X. J. Tan, Q. Li, X. H. Chen, Z. W. Wang, Z. Y. Shi, and Y. Jia, "Simultaneous determination of 13 bioactive compounds in Herba Artemisiae Scopariae (Yin Chen) from different harvest seasons by HPLC-DAD," Journal of Pharmaceutical and Biomedical Analysis, vol. 47, no. 4-5, pp. 847-853, 2008.

[23] Y. Tai, F. Zou, Q. Zhang et al., "Quantitative analysis of eight triterpenoids and two tesquiterpenoids in Rhizoma Alismatis byusing UPLC-ESI/APCI-MS/MS and its application to optimization of best harvest time and crude processing temperature," Journal of Analytical Methods in Chemistry, vol. 14, Article ID 8320171, 2019. 